Article

\title{
Evolution from Natural $\beta$-Carboline Alkaloids to Obtain 1,2,4,9-tetrahydro-3-thia-9-aza-fluorene Derivatives as Potent Fungicidal Agents against Rhizoctonia solani
}

\author{
Junmin $\mathrm{Xi}^{\dagger}{ }^{\dagger}$, Zhijun Zhang ${ }^{\dagger}(\mathbb{D}$, Qi Zhu and Guohua Zhong * \\ Key Laboratory of Crop Integrated Pest Management in South China, Ministry of Agriculture, \\ South China Agricultural University, Guangzhou 510642, China; xijunmin1990@163.com (J.X.); \\ zhangzhijun198803@163.com (Z.Z.); zhuqi1008611@163.com (Q.Z.) \\ * Correspondence: guohuazhong@scau.edu.cn; Tel.: +86-20-852-80308; Fax: +86-20-852-80203 \\ † These authors contributed equally to this work.
}

Received: 5 November 2018; Accepted: 10 December 2018; Published: 14 December 2018

\begin{abstract}
Rice sheath blight, caused by Rhizoctonia solani, is a globally important rice disease and the increasing resistance of this pathogen highlights the need for new active compounds against rice sheath blight. In this study, natural $\beta$-carboline alkaloids were optimized to obtain a series of 1,2,4,9-tetrahydro-3-thia-9-aza-fluorene derivatives and evaluated for their fungicidal activity and mode of action against $R$. solani. Of these compounds, $\mathbf{1 8}$ exhibited significant in vitro fungicidal activity against $R$. solani, with an $\mathrm{EC}_{50}$ value of $2.35 \mu \mathrm{g} / \mathrm{mL}$, and was more active than validamycin A. In vivo bioassay also demonstrated that 18 displayed superior protective and curative activities as compared to validamycin A. Mechanistically, 18 not only induced the loss of mitochondrial membrane potential and accumulation of reactive oxygen species, but also interfered with DNA synthesis. Therefore, compound $\mathbf{1 8}$ displayed pronounced in vitro and in vivo fungicidal activity against $R$. solani and could be used as a potential candidate for the control of rice sheath blight.
\end{abstract}

Keywords: $\beta$-carboline; 1,2,4,9-tetrahydro-3-thia-9-azafluorene; fungicidal activity; Rhizoctonia solani

\section{Introduction}

Rice sheath blight, caused by Rhizoctonia solani [1], is one of the most important and destructive fungal diseases in rice around the world [2], and has caused devastating losses of yield up to $50 \%$ under favorable conditions as well as decreased quality of rice [3,4]. Although a few fungicides are available and have been widely used for the control of rice sheath blight [5], such as validamycin A [6], indiscriminate fungicide usage not only increases the risk of pathogen resistance but also harms the environment and human health [7]. Therefore, the quest for highly-effective fungicides against rice sheath blight with a novel mode of action is imperative.

Natural bioactive products are considered as ideal lead compounds to develop biorational alternatives compared to synthetic agrochemicals [8,9]. $\beta$-Carboline alkaloids and the saturated analogues, dihydro- $\beta$-carboline and tetrahydro- $\beta$-carboline alkaloids, are the main active components from medicinal genus Peganum, such as Peganum harmala, P. multisectum, and P. nigellastrum, which are distributed in the northwest of China [10]. Harmine (1), harmane (2), harmaline (3), harmalol (4), and tetrahydroharmine (5) are the representative harmala alkaloids (Figure 1), and these alkaloids have demonstrated marginal and similar fungicidal activity against several pathogenic fungi including R. solani [11,12], which implies that ring $C$ of $\beta$-carboline is attractive for further optimization. In our previous studies, we introduced the functional groups urea [13] and oxadiazole [14] into the three 
position of $\beta$-carboline and showed an enhancing fungicidal activity against $R$. solani. However, the inflexible property of the $\beta$-carboline scaffold led to the poor solubility of those $\beta$-carboline derivatives. Thus, in this work, we are focused on the modification of ring $C$ of the $\beta$-carboline scaffold, including changing the degrees of saturation and introducing heteroatoms, and providing a potent 1,2,4,9-tetrahydro-3-thia-9-aza-fluorene scaffold which can be used as a novel fungicidal template against $R$. solani. Then, a series of 1,2,4,9-tetrahydro-3-thia-9-aza-fluorene derivatives are synthesized and systematically evaluated for their in vitro and in vivo fungicidal activities against R. solani. Meanwhile, the preliminary mechanism of action are also elucidated.

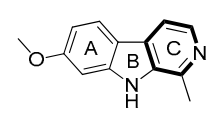

1 Harmine

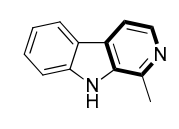

2 Harmane

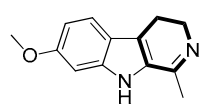

3 Harmaline

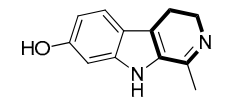

4 Harmalol

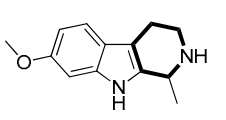

5 Tetrahydroharmine

Figure 1. Representative structures of the $\beta$-carboline alkaloids.

\section{Results and Discussion}

\subsection{Chemistry}

The synthesis of intermediates and target compounds were performed as shown in Figure 2. Following a Fischer indole synthesis protocol, various phenylhydrazine hydrochlorides were reacted with cycloalkanone under acidic condition or bismuth-nitrate catalyst to afford compounds 9-11 and 14-28 [15,16]. Oxidation of $\mathbf{1 1}$ with different ratios of m-chloroperbenzoic acid gave oxide $\mathbf{1 2}$ and dioxide 13 [15]. N-substituted compounds 29-35 were achieved in a good yield through coupling of $\mathbf{1 1}$ and various alkyl halides or acyl chloride under alkaline conditions [15]. Treatment of $\mathbf{3 2}$ with hydrazine hydrate in ethanol obtained acylhydrazone 36, which converted into compound 37 on treatment with 3,4,5-trimethoxybenzaldehyde [17], and into oxadiazole 38 according to our previously reported procedure [14]. $\mathrm{N}$-benzoylation of $\mathbf{1 1}$ was accomplished using 2-chlorobenzoyl chloride in the presence of sodium hydride, furnishing compound 39. All newly synthesized compounds were purified by column chromatography and their structures were confirmed on the basis of ${ }^{1} \mathrm{H}$ NMR (nuclear magnetic resonance) and elemental analysis data.

(a)

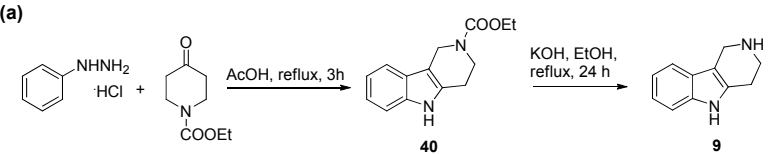

(b)

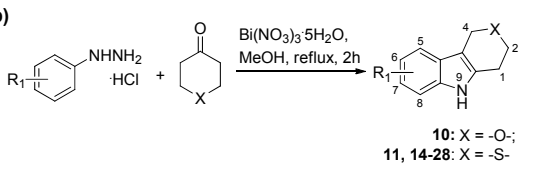

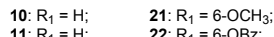

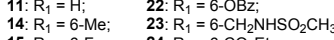

$\begin{array}{ll}\text { 15: } R_{1}=6-\mathrm{F} ; & \text { 24: } \mathrm{R}_{1}=6-\mathrm{CO}_{2} \mathrm{Et} \\ \text { 16: } & \end{array}$

$\begin{array}{ll}\text { 16: } R_{1}=6-C l ; & 25: R_{1}=5-C F_{3} ; \\ \text { 17: } R_{1}=6-B ; & 26: R_{1}=7-C F_{3}\end{array}$

$\begin{array}{ll}17: R_{1}=6-B r ; & 26: R_{1}=7-C F_{3} ; \\ 18: R_{1}=6-C F_{3} ; & 27: R_{1}=8-C F\end{array}$

19: $\mathrm{R}_{1}=6-\mathrm{NO}_{2} ; \quad 28: \mathrm{R}_{1}=5,7-\mathrm{di}-\mathrm{CF}_{3} ;$
20: $\mathrm{R}_{1}=6-\mathrm{OCF}_{3} ;$

(c)
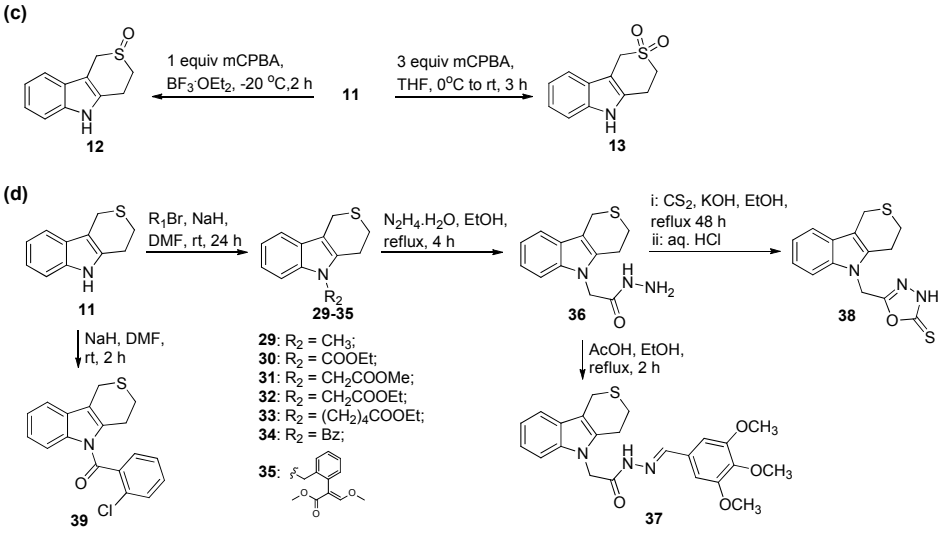

Figure 2. Synthesis of target compounds 9-39. 


\subsection{Biological Activity}

The results of the in vitro and in vivo fungicidal activities of compounds 6-39 against $R$. solani are listed in Tables 1-4 and Figures 3 and 4 with commercial fungicide validamycin A as a positive control.

\subsubsection{In Vitro Fungicidal Activity of Compounds 6-39 against $R$. solani}

Harmine (1) and its analogs $\mathbf{3}$ and 5-13 were screened for their fungicidal activity against $R$. solani and the results presented in Table 1 show that these three $\beta$-carboline alkaloids displayed similar fungicidal activity against $R$. solani, indicating that the $C$ ring of $\beta$-carboline is attractive for further optimization. For example, the activities of harmine (1), harmaline (3), and tetrahydroharmine (5) were $30.25 \%, 29.51 \%$, and $28.31 \%$, respectively, at $100 \mu \mathrm{g} / \mathrm{mL}$. Therefore, the initial round of structure activity relationship (SAR) modifications was directed toward optimization for the $\mathrm{C}$ ring while maintaining the tricyclic core scaffold. First, the phenyl group (7) was substituted for the pyridine moiety (6) and led to a slight improvement in activity, whereas when the $C$ ring was tetrahydropyridine, compound 8 was inactive. Interestingly, tetrahydro- $\gamma$-carboline (9) was approximately 10 -fold more active than the $\beta$-carboline counterpart 8. Second, the influence of the heteroatoms on the $C$ ring was explored; this led to the synthesis of compounds $\mathbf{1 0}$ and 11, which were favorable for activity. Of particular note, the hit compound $\mathbf{1 1}$ displayed the most activity in the series with an $\mathrm{EC}_{50}$ (medium effective concentration) value of $38.58 \mu \mathrm{g} / \mathrm{mL}$ and was 8 -fold more potent than $1\left(\mathrm{EC}_{50}=318.56 \mu \mathrm{g} / \mathrm{mL}\right)$. Oxidation of compound 11 obtained sulfoxide 12 and sulfone 13, which were bereft of activity $\left(\mathrm{EC}_{50}>1000 \mu \mathrm{g} / \mathrm{mL}\right)$. These results indicated that 1,2,4,9-tetrahydro-3-thia-9-aza-fluorene was a potent fungicidal scaffold.

Table 1. In vitro fungicidal activity of compounds 1,3 , and 5-13. ${ }^{\text {a }}$

\begin{tabular}{|c|c|c|c|c|}
\hline \multirow{2}{*}{ Compound } & \multicolumn{2}{|c|}{ Percentage Inhibition (\%) } & \multirow{2}{*}{$\mathrm{EC}_{50}(\mu \mathrm{g} / \mathrm{mL})$} & \multirow{2}{*}{$95 \% \mathrm{CI}^{\mathrm{b}}$} \\
\hline & $100 \mu \mathrm{g} / \mathrm{mL}$ & $10 \mu \mathrm{g} / \mathrm{mL}$ & & \\
\hline harmine (1) & $30.25 \pm 1.11$ & $18.28 \pm 0.76$ & 318.56 & $255.10-441.98$ \\
\hline harmaline (3) & $29.51 \pm 1.81$ & $14.45 \pm 3.76$ & $-\mathrm{c}$ & $-c$ \\
\hline tetrahydroharmine (5) & $28.31 \pm 6.84$ & $9.03 \pm 1.04$ & $-c$ & $-c$ \\
\hline$\beta$-carboline (6) & $34.04 \pm 1.21$ & $16.67 \pm 1.34$ & 241.52 & 109.44-303.76 \\
\hline carbazole $(7)$ & $56.67 \pm 1.69$ & $26.67 \pm 2.21$ & $-c$ & $-c$ \\
\hline tetrahydro- $\beta$-carboline (8) & $5.37 \pm 5.45$ & 0 & $-c$ & $-c$ \\
\hline tetrahydro- $\gamma$-carboline (9) & $63.95 \pm 1.33$ & $10.11 \pm 0.08$ & 79.22 & $71.08-89.41$ \\
\hline 10 & $69.66 \pm 1.21$ & $22.47 \pm 1.01$ & 66.89 & $38.42-94.17$ \\
\hline 11 & $91.02 \pm 2.31$ & $32.45 \pm 3.87$ & 38.58 & $25.45-51.97$ \\
\hline 12 & $3.67 \pm 1.69$ & 0.00 & $>1000$ & $-c$ \\
\hline 13 & $6.35 \pm 1.54$ & 0.00 & $>1000$ & $-c$ \\
\hline validamycin $\mathrm{A}$ & $36.68 \pm 1.09$ & $18.91 \pm 0.49$ & 183.00 & $162.62-210.66$ \\
\hline
\end{tabular}

${ }^{\mathrm{a}}$ Values are the mean $\pm \mathrm{SD}$ of three replicates. ${ }^{\mathrm{b}} 95 \%$ confidence interval. ${ }^{\mathrm{c}}$ not calculated.

The effects of the substituents and substituted position on the A ring of 1,2,4,9-tetrahydro-3-thia9-aza-fluorene were subsequently investigated. As shown in Table 2, small groups (15-20) were favorable for activity, while bulky groups $(\mathbf{2 2 , 2 3})$ were detrimental to activity. Compounds 15-20 bearing electron-withdrawing groups were more potent than $\mathbf{1 1}$, whereas electron-donating groups $(\mathbf{1 4}, 21)$ were significantly less active. For example, compounds 17-19 showed the best potency with respective $\mathrm{EC}_{50}$ values of $2.94,2.35$, and $3.79 \mu \mathrm{g} / \mathrm{mL}$. For the effect of the substituted position on the ring $\mathrm{A}$, the fungicidal activity of compounds $\left(\mathbf{1 8 , 2 5 - 2 7 )}\right.$ increased following $6-\mathrm{CF}_{3}>5-\mathrm{CF}_{3}>8-\mathrm{CF}_{3}$ $>7-\mathrm{CF}_{3}$. In comparison to monosubstituted compounds 25 and 26, disubstituted compound 28 was much less potent. Finally, the biological data for 29-39 with a focus on varying substituents was in the 9-position of the 1,2,4,9-tetrahydro-3-thia-9-aza-fluorene moiety. Here, it can be seen quite clearly that the structural changes in general were detrimental to activity and no favorable substitution could be found for the 9-position, even after extensive probing with a variety of diverse groups (29-39). 
Table 2. In vitro fungicidal activity of compounds 14-39. ${ }^{\text {a }}$

\begin{tabular}{|c|c|c|c|c|}
\hline \multirow{2}{*}{ Compound } & \multicolumn{2}{|c|}{ Percentage Inhibition (\%) } & \multirow{2}{*}{$\mathrm{EC}_{50}(\mu \mathrm{g} / \mathrm{mL})$} & \multirow{2}{*}{$95 \% \mathrm{CI}^{\mathrm{c}}$} \\
\hline & $100 \mu \mathrm{g} / \mathrm{mL}$ & $10 \mu \mathrm{g} / \mathrm{mL}$ & & \\
\hline 14 & $68.27 \pm 1.37$ & $48.05 \pm 2.10$ & 37.02 & $15.40-52.18$ \\
\hline 15 & $90.80 \pm 0.80$ & $57.24 \pm 2.76$ & 10.55 & $0.10-19.73$ \\
\hline 16 & $89.88 \pm 0.80$ & $66.89 \pm 2.38$ & 6.84 & $1.91-13.04$ \\
\hline 17 & $93.56 \pm 0.80$ & $81.61 \pm 2.11$ & 2.94 & $0.23-6.34$ \\
\hline $18^{\mathrm{b}}$ & $88.38 \pm 0.87$ & $82.83 \pm 0.87$ & 2.35 & $0.42-5.72$ \\
\hline 19 & $89.89 \pm 1.33$ & $72.15 \pm 3.08$ & 3.79 & $0.19-7.60$ \\
\hline $20^{b}$ & $75.53 \pm 0.73$ & $55.27 \pm 2.64$ & 10.86 & $2.41-24.47$ \\
\hline 21 & $68.54 \pm 1.36$ & $37.09 \pm 1.33$ & 40.15 & $16.41-71.36$ \\
\hline 22 & $8.44 \pm 3.65$ & 0.00 & $-d$ & $-d$ \\
\hline $23^{b}$ & 0.00 & 0.00 & $-d$ & $-d$ \\
\hline 24 & $79.77 \pm 1.69$ & $43.82 \pm 1.33$ & 26.69 & $14.50-37.00$ \\
\hline $25^{b}$ & $91.92 \pm 1.75$ & $52.53 \pm 1.75$ & 14.85 & $1.15-25.21$ \\
\hline $26^{b}$ & $83.84 \pm 3.15$ & $40.91 \pm 1.52$ & 22.81 & $9.56-33.56$ \\
\hline $27^{b}$ & $84.85 \pm 0.00$ & $59.09 \pm 1.51$ & 7.46 & $4.50-11.21$ \\
\hline $28^{b}$ & $64.65 \pm 0.87$ & $28.28 \pm 2.31$ & 54.55 & $39.01-74.92$ \\
\hline 29 & $75.39 \pm 1.21$ & $36.18 \pm 1.34$ & 50.93 & $29.23-83.72$ \\
\hline $30^{b}$ & $50.65 \pm 2.25$ & $42.85 \pm 1.33$ & 93.08 & $34.27-172.92$ \\
\hline $31^{b}$ & $67.41 \pm 1.69$ & $38.20 \pm 2.33$ & 40.38 & $11.35-56.72$ \\
\hline $32^{b}$ & $50.66 \pm 2.97$ & $20.21 \pm 0.08$ & 93.42 & $56.84-372.27$ \\
\hline $33^{b}$ & $87.64 \pm 1.63$ & $49.43 \pm 3.72$ & 25.65 & $6.42-46.82$ \\
\hline 34 & $56.18 \pm 1.69$ & $38.20 \pm 1.21$ & 67.85 & $36.64-140.78$ \\
\hline $35^{b}$ & $56.18 \pm 1.33$ & $29.21 \pm 0.87$ & 83.84 & $64.84-122.16$ \\
\hline $36^{b}$ & $4.12 \pm 0.71$ & 0.00 & $-d$ & $-d$ \\
\hline $37^{b}$ & $6.33 \pm 1.21$ & 0.00 & $-d$ & $-d$ \\
\hline $38^{b}$ & $37.37 \pm 0.74$ & $4.12 \pm 0.91$ & 120.49 & $110.03-135.48$ \\
\hline $39^{b}$ & $38.82 \pm 1.47$ & $21.94 \pm 3.18$ & 149.44 & $117.28-226.41$ \\
\hline
\end{tabular}

a Values are the mean \pm SD of three replicates. ${ }^{b}$ novel compound. ${ }^{c} 95 \%$ confidence interval. ${ }^{\mathrm{d}}$ not calculated.

\subsubsection{In Vivo Protective and Curative Effects against Rice Sheath Blight}

Among the compounds tested for fungicidal activity in vitro, compounds 11, 14-19, and 21 were potent against $R$. solani and, therefore, were selected to evaluate the in vivo protective effect using detached leaf assay. As shown in Table 3 and Figure 3, most of these compounds exhibited excellent in vivo protective potency. Fortunately, compounds 17-19 possessed the highest fungicidal activity and the inhibitory effect at $100 \mathrm{\mu g} / \mathrm{mL}$ was up to $97.41 \%, 99.87 \%$ and $100 \%$, respectively, which was comparable in activity to the commercial fungicide validamycin $\mathrm{A}(100 \%$ at $100 \mu \mathrm{g} / \mathrm{mL})$.

Table 3. In vivo protective activity against Rhizoctonia solani using detached leaf assay.

\begin{tabular}{cccc}
\hline Treatment & Concentration $(\boldsymbol{\mu g} / \mathbf{m L})$ & Lesion Length ${ }^{\text {a }}(\mathbf{c m} \pm$ SE) & Control Efficacy (\%) \\
\hline \multirow{2}{*}{$\mathbf{1 1}$} & 200 & $0.61 \pm 0.40^{* *}$ & 92.47 \\
& 100 & $1.12 \pm 0.45^{* *}$ & 86.17 \\
$\mathbf{1 4}$ & 200 & $0.77 \pm 0.38^{* *}$ & 90.49 \\
& 100 & $1.69 \pm 0.55^{* *}$ & 79.14 \\
$\mathbf{1 5}$ & 200 & $0.29 \pm 0.19^{* *}$ & 96.42 \\
& 100 & $1.31 \pm 0.56^{* *}$ & 83.83 \\
$\mathbf{1 6}$ & 200 & $0.17 \pm 0.17^{* *}$ & 97.90 \\
& 100 & $0.90 \pm 0.45^{* *}$ & 88.89 \\
$\mathbf{1 7}$ & 200 & $\mathbf{0}$ & $\mathbf{1 0 0}$ \\
& 100 & $0.21 \pm 0.24^{* *}$ & 97.41 \\
$\mathbf{1 8}$ & 200 & $\mathbf{0}$ & $\mathbf{1 0 0}$ \\
& 100 & $0.01 \pm 0.05^{* *}$ & 99.87 \\
$\mathbf{1 9}$ & 200 & $\mathbf{0}$ & $\mathbf{1 0 0}$ \\
& 100 & $\mathbf{0}^{* *}$ & $\mathbf{1 0 0}$ \\
$\mathbf{2 1}$ & 200 & $0.71 \pm 0.31^{* *}$ & 91.23 \\
& 100 & $1.69 \pm 0.46^{* *}$ & 79.14 \\
\hline
\end{tabular}


Table 3. Cont.

\begin{tabular}{cccc}
\hline Treatment & Concentration $(\mu \mathrm{g} / \mathrm{mL})$ & Lesion Length ${ }^{\mathrm{a}}(\mathbf{c m} \pm \mathrm{SE})$ & Control Efficacy $(\%)$ \\
\hline \multirow{2}{*}{ validamycin A } & 200 & $0^{* *}$ & 100 \\
control & 100 & $0^{* *}$ & 100 \\
${ }^{* * *}$ represents $p<0.01 .^{\text {a }}$ Values are the mean \pm SD of 20 leaves. ${ }^{\mathrm{b}}$ not calculated.
\end{tabular}

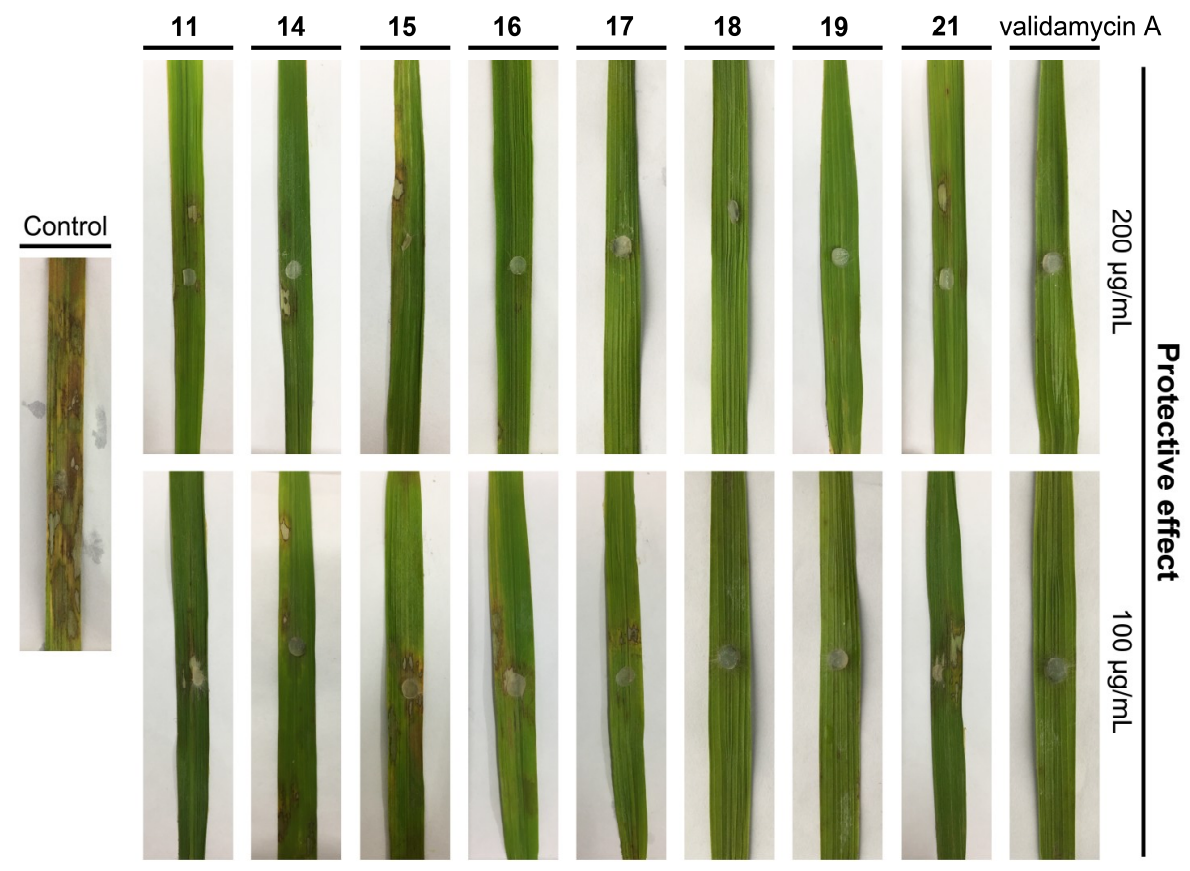

Figure 3. The in vivo protective effect of selected compounds against $R$. solani using detached leaf assay.

The most potent compounds 17-19 were further assessed for their protective and curative effects against $R$. solani under a greenhouse experiment, and the results were presented in Table 4 and Figure 4 . All of three compounds displayed significant in vivo fungicidal activity and effectively controlled rice sheath blight, of which compound $\mathbf{1 8}$ displayed the best potency against $R$. solani. For instance, after seven days transplantation, the protective and curative activities of $18(81.16 \%$ and $81.58 \%$ at $200 \mu \mathrm{g} / \mathrm{mL} ; 73.66 \%$ and $75.59 \%$ at $100 \mu \mathrm{g} / \mathrm{mL})$ and $19(79.44 \%$ and $79.01 \%$ at $200 \mu \mathrm{g} / \mathrm{mL} ; 65.10 \%$ and $68.31 \%$ at $100 \mu \mathrm{g} / \mathrm{mL})$ in vivo were more active than those of validamycin $\mathrm{A}(78.80 \%$ and $75.80 \%$ at $200 \mu \mathrm{g} / \mathrm{mL} ; 65.74 \%$ and $67.45 \%$ at $100 \mu \mathrm{g} / \mathrm{mL})$.

Table 4. In vivo protective and curative effects against $R$. solani using greenhouse experiment.

\begin{tabular}{cccccc}
\hline \multirow{2}{*}{ Treatment } & $\begin{array}{c}\text { Concentration } \\
(\mu \mathrm{g} / \mathrm{mL})\end{array}$ & $\begin{array}{c}\text { Lesion Length } \\
\mathbf{a}(\mathbf{c m} \pm \mathbf{S E})\end{array}$ & $\begin{array}{c}\text { Control } \\
\text { Efficacy (\%) }\end{array}$ & $\begin{array}{c}\text { Lesion Length } \\
(\mathbf{c m} \pm \mathbf{S E})\end{array}$ & $\begin{array}{c}\text { Control } \\
\text { Efficacy (\%) }\end{array}$ \\
\cline { 3 - 6 } & 200 & $\mathbf{0 . 9 2} \pm \mathbf{0 . 5 9 * *}$ & $\mathbf{8 0 . 3 0}$ & $\mathbf{0 . 9 9} \pm \mathbf{0 . 3 3} * *$ & $\mathbf{7 8 . 8 0}$ \\
$\mathbf{1 7}$ & 100 & $\mathbf{1 . 5 5} \pm \mathbf{0 . 7 3} * *$ & $\mathbf{6 6 . 8 1}$ & $1.76 \pm 0.88^{* *}$ & 62.31 \\
$\mathbf{1 8}$ & 200 & $\mathbf{0 . 8 8} \pm \mathbf{0 . 4 7} * *$ & $\mathbf{8 1 . 1 6}$ & $\mathbf{0 . 8 6} \pm \mathbf{0 . 3 3} * *$ & $\mathbf{8 1 . 5 8}$ \\
& 100 & $\mathbf{1 . 2 3} \pm \mathbf{0 . 6 1} * *$ & $\mathbf{7 3 . 6 6}$ & $\mathbf{1 . 1 4} \pm \mathbf{0 . 3 9} * *$ & $\mathbf{7 5 . 5 9}$ \\
$\mathbf{1 9}$ & 200 & $\mathbf{0 . 9 6} \pm \mathbf{0 . 5 0} * *$ & $\mathbf{7 9 . 4 4}$ & $\mathbf{0 . 9 8} \pm \mathbf{0 . 4 0} * *$ & $\mathbf{7 9 . 0 1}$ \\
& 100 & $1.63 \pm 0.45^{* *}$ & 65.10 & $\mathbf{1 . 4 8} \pm \mathbf{0 . 5 0} * *$ & $\mathbf{6 8 . 3 1}$ \\
validamycin A & 200 & $0.99 \pm 0.43^{* *}$ & 78.80 & $1.13 \pm 0.51^{* *}$ & 75.80 \\
& 100 & $1.60 \pm 0.60^{* *}$ & 65.74 & $1.52 \pm 0.64^{* *}$ & 67.45 \\
\hline
\end{tabular}

${ }^{* *}$ represents $p<0.01 .{ }^{\text {a }}$ Values are the mean \pm SD of 20 plants. 


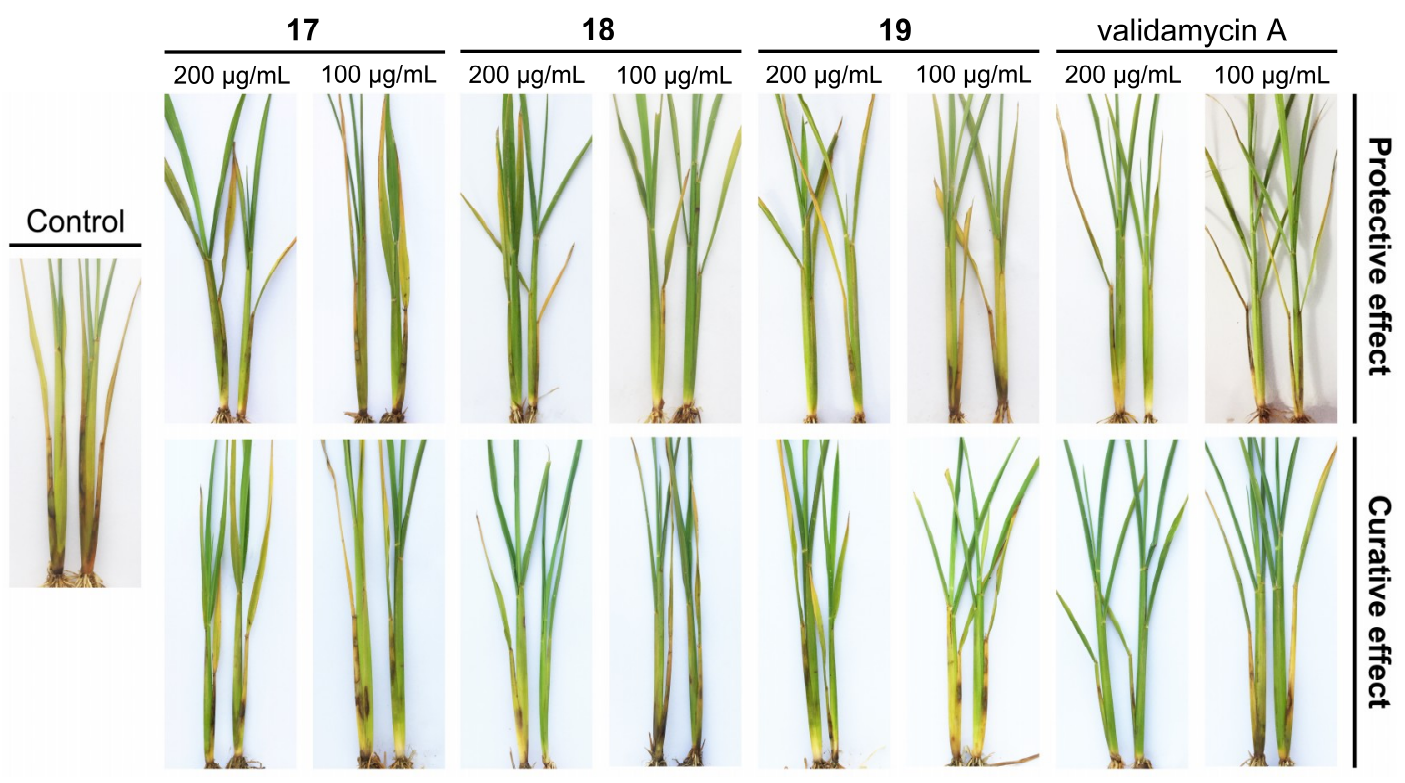

Figure 4. The in vivo protective and curative activities of compounds 17-19 against $R$. solani.

\subsection{Preliminary Mode of Action of Compound 18 against R. solani}

\subsubsection{Effect of $\mathbf{1 8}$ on the hyphae morphology of $R$. solani}

The untreated $R$. solani mycelia grew smoothly with a low density, and the colony possessed a round and regular edge. However, after treatment with 18, the edge of the colony became irregular and the mycelia was dense compared to the control mycelia, indicating that $\mathbf{1 8}$ seriously inhibited the growth of mycelia.

Scanning electron microscopy (SEM) was used to reveal the morphological variations of $R$. solani hyphae in response to 18. As shown in Figure 5a,b, the mycelia were loose and plump with a smooth surface and an intact structure in the absence of 18 . In contrast, after treatment with $50 \mu \mathrm{g} / \mathrm{mL} 18$ for $48 \mathrm{~h}$, the mycelia were dense with a coarse surface and appeared severely shrunken and distorted with locally folding and entangling (Figure $5 c, d$ ). This prominent morphological change might have resulted from the destruction of cellular organelles.
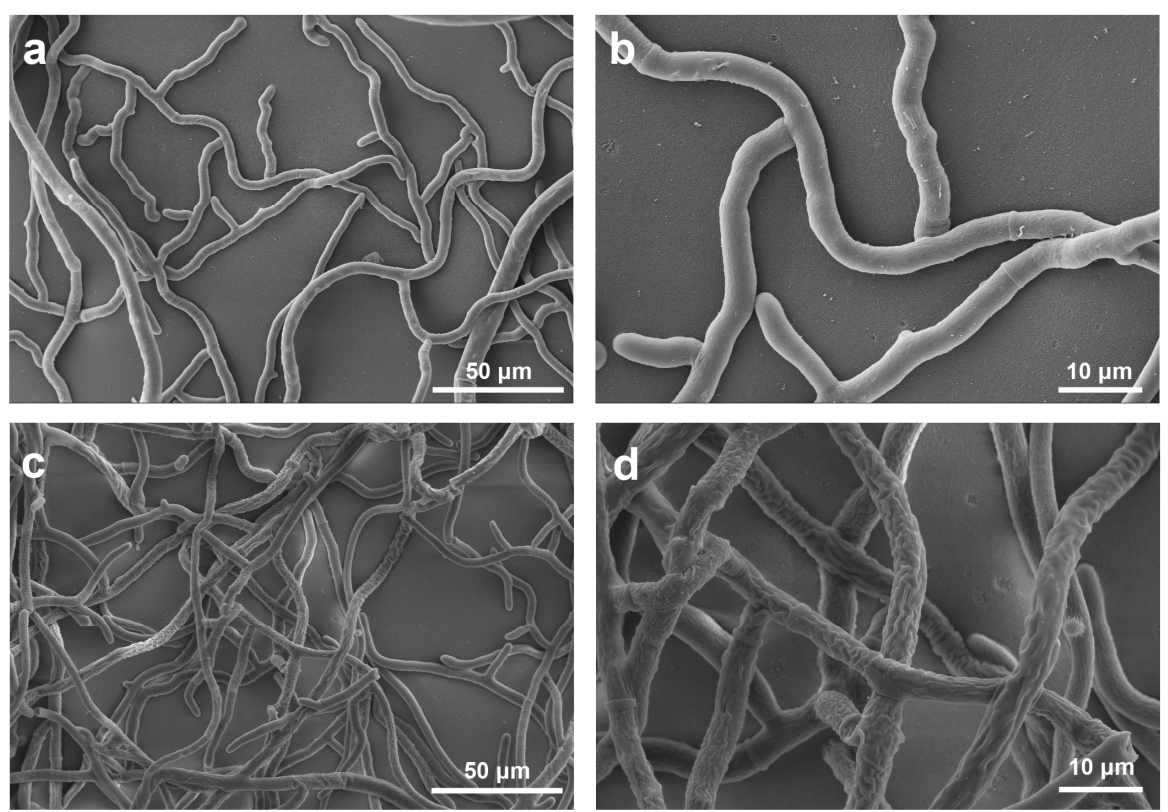

Figure 5. SEM of $R$. solani hyphae treated with $0(\mathbf{a}, \mathbf{b})$ or $50 \mu \mathrm{g} / \mathrm{mL} \mathbf{1 8}(\mathbf{c}, \mathbf{d})$. 
Transmission electron microscopy (TEM) observation revealed that the untreated hyphal cell displayed the characteristic ultrastructural features with distinct cell membranes (CMs), cell walls (CWs), and septa (S), and abundant organelles in cytoplasm, such as vacuole (V) and mitochondria (M) (Figure 6a-d). However, after exposure to 18, the organelles became disorganized and caused profound changes. For example, a slight swelling of the mitochondrial matrix, disappearance of mitochondrial intermembrane space, and an obvious vacuolization were observed (Figure $6 \mathrm{e}, \mathrm{f}, \mathrm{h}$ ). While the cell walls and septa of the 18-treated hyphae were almost unaffected (Figure 6f,g).

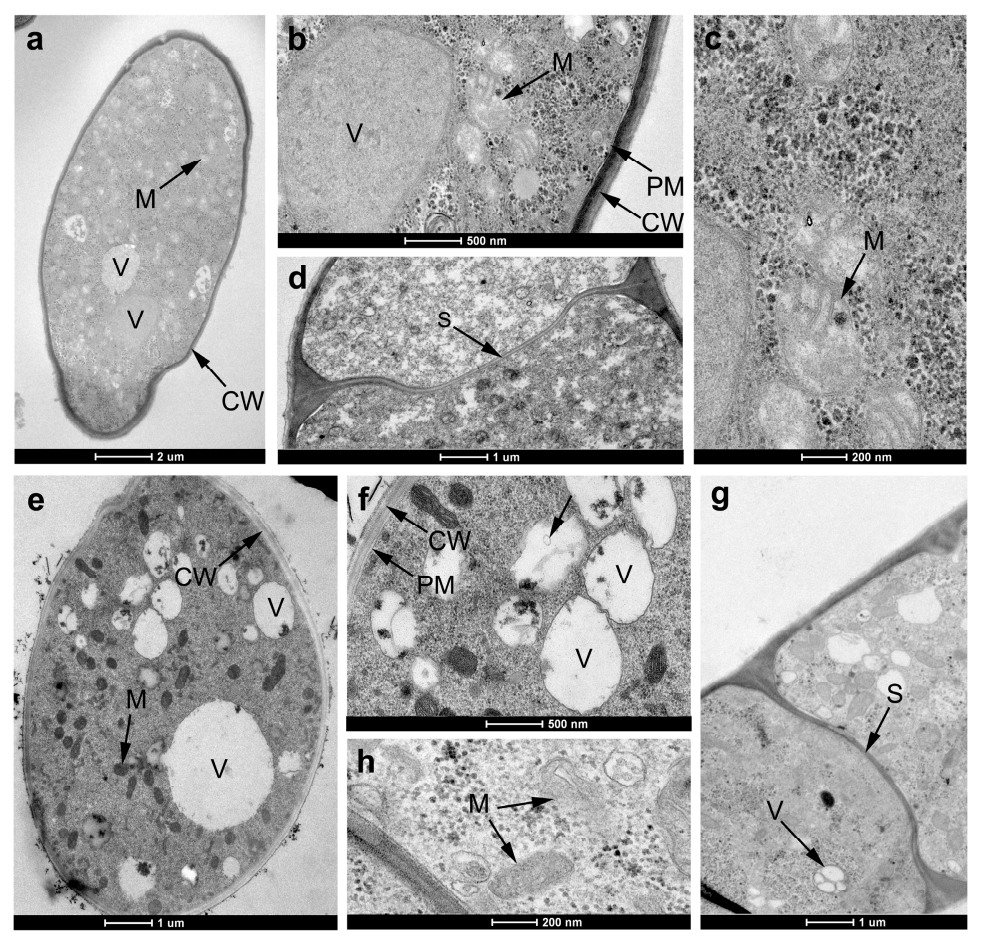

Figure 6. TEM of $R$. solani hyphae treated with 0 (a-d) or $50 \mu \mathrm{g} / \mathrm{mL} \mathbf{1 8}(\mathbf{e}-\mathbf{h})$. (a) Transverse of control hyphae and many organelles were observed such as mitochondria $(\mathrm{M})$ and vacuole $(\mathrm{V}) ;(\mathbf{b})$ cell wall (CW) and plasma membrane (PM) of untreated hyphae; (c) mitochondria of untreated hyphae; (d) longitudinal of untreated hyphae, and spectra (S) was uniform; (e,f) transverse of 18-treated hyphae; (g) longitudinal of 18-treated hyphae (loss of matrix in vacuoles and obvious vacuolization); (h) mitochondria of 18-treated hyphae was swollen.

\subsubsection{Effect of $\mathbf{1 8}$ on the Endogenous ROS Production and Cell Membrane Permeability}

Reactive oxygen species (ROS) plays an important role in cell death and involves fungicidal action [18]. To examine the effect of $\mathbf{1 8}$ on the intracellular ROS production, an ROS assay was performed on $R$. solani using DCFH-DA ( $2^{\prime}, 7^{\prime}$-Dichlorodihydrofluorescein diacetate) as an ROS indicator. Interestingly, the significant fluorescence of the 18-treated mycelia was obviously observed compared to that of the untreated mycelia (Figure 7a,b), which parallels our previous findings for $\beta$-carboline derivatives [14]. Reactive oxygen species accumulation might induce permeabilization of fungal cell membranes through disintegrating the phospholipid residues [19]. Therefore, we next evaluated the conductivity changes of the hyphae to reflect alterations in cell membrane permeability, and expectedly, the results implied that $\mathbf{1 8}$ had a weak effect on cell membrane permeability (Figure 7h), which was similar to what we previously described [14]. 

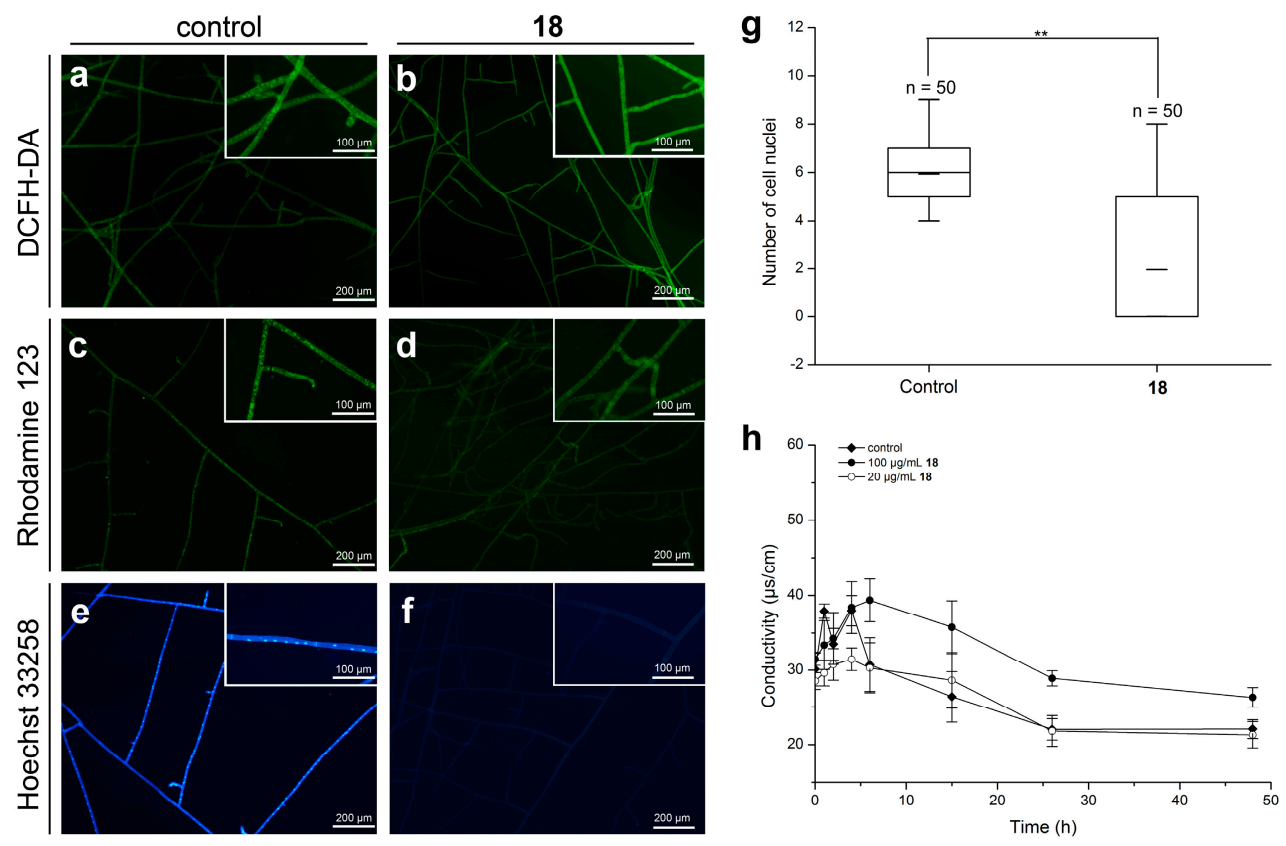

Figure 7. The mode of action of compound 18 against $R$. solani. (a,b) Fluorescent micrographs of the hyphae stained with DCFH-DA to assess endogenous reactive oxygen species (ROS) production; (c,d) fluorescent micrographs of the hyphae stained with Rhodamine 123 to evaluate mitochondrial membrane potential (MMP); (e,f) nuclear morphology of the hyphae stained by Hoechst 33258; (g) the number of nuclei per cell of somatic hyphae treated with 0 or $50 \mu \mathrm{g} / \mathrm{mL} \mathrm{18;} \mathrm{(**} p<0.01)$; (h) the conductivity of the hyphae suspensions during different time exposure to 18 was measured to assess cell membrane permeability.

\subsubsection{Effect of $\mathbf{1 8}$ on the mitochondrial membrane potential (MMP)}

As an indicator of the energetic atate of the mitochondria, MMP is used to evaluate the activity of the mitochondrial proton pumps, electrogenic transport systems, and the activation of the mitochondrial permeability transition [20]. The effect of $\mathbf{1 8}$ on MMP was elucidated using the potential-dependent distributional probe Rhodamine 123. As shown in Figure 7c,d, compared to the control hyphae, a dramatic decrease of fluorescence intensity in the 18-treated hyphae was observed. This finding suggested that $\mathbf{1 8}$ could induce the loss of mitochondria dysfunction, and the subsequent dysfunction of mitochondria, thereby accelerating cell death.

\subsubsection{Effect of $\mathbf{1 8}$ on the Nuclear Morphology of R. solani}

The nuclear morphology of $R$. solani hyphae in response to $\mathbf{1 8}$ was observed using Hoechst 33258 . The results presented in Figure $7 \mathrm{e}, \mathrm{f}$ showed that the nucleus of the untreated hyphal cells displayed uniform blue color and could be observed as intense, discrete signals. However, after treatment of 18, the nucleus showed faint signals, and most of the hyphae did not show discrete nuclear signals. Meanwhile, a quantitative analysis was performed to detect the number of nuclei per hyphal cell with or without 18 treatment. As shown in Figure 7g, a dramatic drop in the number of nuclei per 18-treated hyphal cell was observed, with an average of 1.96 nuclei per cell, compared to that in untreated hyphae (average 5.94 nuclei). Similar results were seen in our previous work [14]. Taken together, these results indicated that compound $\mathbf{1 8}$ could interfere with DNA synthesis by reducing DNA contents and the number of cell nuclei. 


\section{Materials and Methods}

\subsection{Chemicals}

All reagents and solvents were of reagent grade or purified according to standard methods [21] before use. Reactions were monitored by thin-layer chromatography with silica gel plates using silica gel 60 GF254 (Qingdao Haiyang Chemical Co., Ltd., Qingdao, China). The ${ }^{1} \mathrm{H}-\mathrm{NMR}$ spectra were recorded on a Bruker Avance-600 superconducting nuclear magnetic resonance instrument (Bruker Company, Bremen, Gemany). The chemical synthesis and structural characterization of compounds 9-39 are shown in the Supplementary Materials.

\subsection{Biological Assay}

\subsubsection{In Vitro Fungicidal Activity against R. solani}

The test fungi R. solani GD-118 was provided by Zhou of the Guangdong Province Key Laboratory of Microbial Signals and Disease Control, South China Agricultural University. The in vitro fungicidal activity of compounds $\mathbf{1}$ and 6-39 were evaluated according to our previously reported method with validamycin $\mathrm{A}$ as a positive control [13].

\subsubsection{In Vivo Protective Activity against R. solani using Detached Leaf Assay}

The detached leaf assay was performed to assess the in vivo protective activity of selected compounds using our previously reported method [13]. Healthy paddy leaves were cut $(10 \mathrm{~cm}$ in length), sprayed with compounds (200 and $100 \mu \mathrm{g} / \mathrm{mL}$ ), and then inoculated with strain $R$. solani after dryness. The efficacy of disease control was calculated by the following formula after cultivation at $25^{\circ} \mathrm{C}$ for 5 days.

$$
\text { Protective efficacy }(\%)=\frac{\mathrm{A}_{0}-\mathrm{A}_{1}}{\mathrm{~A}_{0}} \times 100
$$

where $A_{0}$ is the diameter of the negative control, and $A_{1}$ is the diameter of the lesion after treatment.

\subsubsection{In Vivo Protective and Curative Activities against $R$. solani using Greenhouse Experiment}

The rice cultivar (Xiangyazhan) was planted following our previously reported method [14]. The plants were sprayed with compounds 17-19 (200 and $100 \mu \mathrm{g} / \mathrm{mL})$ and subsequently cultivated at $25^{\circ} \mathrm{C}$ for $24 \mathrm{~h}$ before inoculation with $R$. solani by placing a fungus disc $(0.6 \mathrm{~cm}$ in diameter $)$ on the leaf sheaf of each plant. However, for the curative activity, the rice plants were sprayed with compounds (200 and $100 \mu \mathrm{g} / \mathrm{mL}$ ) after inoculation with $R$. solani for $24 \mathrm{~h}$. Validamycin A was used as a positive control, and each treatment was replicated for 20 plants. The diameters of symptoms were measured after inoculation for 7 days and the efficacy of disease control was calculated.

\subsection{Scanning Electron Microscopy (SEM)}

After treatment with $50 \mu \mathrm{g} / \mathrm{mL} 18$ for $48 \mathrm{~h}, R$. solani mycelia tips $(0.5 \mathrm{~cm})$ were cut, treated with $2.5 \%$ of glutaraldehyde at $4{ }^{\circ} \mathrm{C}$, and subsequently fixed with $1 \%(w / v)$ osmium tetraoxide solution after being rinsed with $0.1 \mathrm{M}$ phosphate buffer (PBS, $\mathrm{pH}=7.4$ ) three times. The samples were dehydrated using a series of ethanol solutions (30\%, 50\%, 70\%, 80\%, 90\%, and 100\%), dried at critical point, mounted, gold-sprayed, and then observed under a XL-30-ESEM scanning electron microscope (FEI, Eindhoven, Netherlands) [22].

\subsection{Transmission Electron Microscopy (TEM)}

The dehydrated mycelial blocks were cut into thin sections and then double-stained with uranyl acetate and lead citrate after being embedded in resin, and the samples were observed with a TECNAI $\mathrm{G}^{2} 12$ (FEI) transmission electron microscope. 


\subsection{Determination of ROS Generation}

The DCFH-DA staining was used to detect the endogenous ROS generation as described previously [19]. Briefly, after being treated with $50 \mu \mathrm{g} / \mathrm{mL} 18$ for $48 \mathrm{~h}$, $R$. solani mycelia tips $(0.6 \mathrm{~cm})$ were cut and then placed on a sterile slide in a 9-cm culture dish before continued incubation at $25^{\circ} \mathrm{C}$ for $24 \mathrm{~h}$. The PDA medium was removed, and the hyphae were stained with $10 \mu \mathrm{M}$ DCFH-DA solution (Beyotime, Shanghai, China) and incubated at $37^{\circ} \mathrm{C}$ for $30 \mathrm{~min}$ in the darkness. The samples were observed using a fluorescence microscopy (Nikon ECLIPES 80 i, Tokyo, Japan).

\subsection{Determination of $M M P$}

The effect of compound $\mathbf{1 8}$ on the MMP of R. solani was evaluated using Rhodamine 123 staining [14]. The hyphae were stained with $1 \mathrm{~mL}$ of $1 \mu \mathrm{M}$ Rhodamine 123 solution (Beyotime) and then incubated at $37{ }^{\circ} \mathrm{C}$ for $30 \mathrm{~min}$ in the darkness. The samples were observed under a fluorescence microscopy.

\subsection{Karyological Analysis}

The hyphae were treated with a stain-fixative at $4{ }^{\circ} \mathrm{C}$ overnight, and then stained with $1 \mathrm{~mL}$ Hoechst 33258 solution (Beyotime) at $25^{\circ} \mathrm{C}$ for $10 \mathrm{~min}$ after being washed twice with $0.1 \mathrm{M}$ PBS. The samples were observed under a fluorescence microscopy [23].

\subsection{Detection of Cell Membrane Permeability}

The conductivity changes of $R$. solani mycelial exposed to $\mathbf{1 8}$ were evaluated to reflect alterations in cell membrane permeability according to our previously reported method [14].

\section{Conclusions}

In conclusion, optimization of ring $C$ of natural $\beta$-carboline alkaloids obtained a series of 1,2,4,9-tetrahydro-3-thia-9-aza-fluorene derivatives and their fungicidal activity and preliminary mode of action against $R$. solani were also investigated. The results showed that compound $\mathbf{1 8}$ displayed the most activity with an $\mathrm{EC}_{50}$ value of $2.35 \mu \mathrm{g} / \mathrm{mL}$, and was approximately 80 -fold more potent than validamycin A. In vivo testing also indicated that $\mathbf{1 8}$ could effectively control rice sheath blight caused by $R$. solani and showed better protective and curative activities than validamycin A. Although the preliminary mechanistic study demonstrated that compound 18 might act on the mitochondria, induce loss of MMP and accumulation of ROS, and interfere with DNA synthesis that exerted its fungicidal activity, the specific biological target or targets of $\mathbf{1 8}$ remain unknown. Further studies on structural optimization and target identification are in progress.

Supplementary Materials: Supplementary materials can be found at http:/ / www.mdpi.com/1422-0067/19/12/ 4044/s1.

Author Contributions: Writing—original draft preparation, J.X.; methodology, Z.Z. and Q.Z.; writing一review and editing, Z.Z. and G.Z.; supervision, G.Z.

Acknowledgments: This work was financially supported by the National Natural Science Foundation of China (Grant No. 31572335), the Public Welfare Industry (Agriculture) Special Scientific Funds of China (Grant No. 201303017), and the Natural Science Foundation of Guangdong Province, China (Grant No. 2014A030313461).

Conflicts of Interest: The authors declare no conflict of interest.

\section{References}

1. Miyake, I. Studien ueber die Pilze der Reispflanze in Japan. J. Coll. Agric. Tokyo 1910, 11, 237-251.

2. Groth, D.E. Azoxystrobin rate and timing effects on rice sheath blight incidence and severity and rice grain and milling yields. Plant Dis. 2005, 89, 1171-1174. [CrossRef]

3. Lee, F.N.; Rush, M.C. Rice sheath blight: A major rice disease. Plant Dis. 1983, 67, 829-832. [CrossRef] 
4. Marchetti, M.A. Potential impact of sheath blight on yield and milling quality of short-statured rice lines in the Southern United States. Plant Dis. 1983, 67, 162-165. [CrossRef]

5. Boukaew., S.; Klinmanee, C.; Prasertsan, P. Potential for the integration of biological and chemical control of sheath blight disease caused by Rhizoctonia solani on rice. World J. Microbiol. Biotechnol. 2013, 29, 1885-1893. [CrossRef] [PubMed]

6. Mew, T.W. Applying rice seed-associated antagonistic bacteria to manage rice sheath blight in developing countries. Plant Dis. 2004, 88, 557-564. [CrossRef]

7. Zhang, C.Q.; Liu, Y.H.; Ma, X.Y.; Feng, Z.; Ma, Z.H. Characterization of sensitivity of Rhizoctonia solani, causing rice sheath blight, to mepronil and boscalid. Crop Prot. 2009, 28, 381-386. [CrossRef]

8. Isman, M.B. Botanical insecticides, deterrents, and repellents in modern agriculture and an increasingly regulated world. Ann. Rev. Entomol. 2006, 51, 45-66. [CrossRef]

9. Rosell, G.; Quero, C.; Coll, J.; Guerrero, A. Biorational insecticides in pest management. J. Pestic. Sci. 2008, 33, 103-121. [CrossRef]

10. Li, S.P.; Cheng, X.M.; Wang, C.H. A review on traditional uses, phytochemistry, pharmacology, pharmacokinetics and toxicology of the genus Peganum. J. Ethnopharmacol. 2017, 203, 127-162. [CrossRef]

11. Song, H.; Liu, Y.; Liu, Y.; Wang, L.; Wang, Q. Synthesis and antiviral and fungicidal activity evaluation of $\beta$-carboline, dihydro- $\beta$-carboline, tetrahydro- $\beta$-carboline alkaloids, and their derivatives. J. Agric. Food Chem. 2014, 62, 1010-1018. [CrossRef]

12. Li, Z.B.; Chen, S.H.; Zhu, S.W.; Luo, J.J.; Zhang, Y.M.; Weng, Q.F. Synthesis and fungicidal activity of $\beta$-carboline alkaloids and their derivatives. Molecules 2015, 20, 13941-13957. [CrossRef]

13. Zhang, Z.J.; Zeng, Y.; Jiang, Z.Y.; Shu, B.S.; Sethuraman, V.; Zhong, G.H. Design, synthesis, fungicidal property and QSAR studies of novel $\beta$-carbolines containing urea, benzoylthiourea and benzoylurea for the control of rice sheath blight. Pest Manag. Sci. 2018, 74, 1736-1746. [CrossRef] [PubMed]

14. Zhang, Z.J.; Jiang, Z.Y.; Zhu, Q.; Zhong, G.H. Discovery of $\beta$-carboline oxadiazole derivatives as fungicidal agents against rice sheath blight. J. Agric. Food Chem. 2018, 66, 9598-9607. [CrossRef] [PubMed]

15. De Vreese, R.; Depetter, Y.; Verhaeghe, T.; Desmet, T.; Benoy, V.; Haeck, W.; Van Den Bosch, L.; D’hooghe, M. Synthesis and SAR assessment of novel Tubathian analogs in the pursuit of potent and selective HDAC6 inhibitors. Org. Biomol. Chem. 2016, 14, 2537-2549. [CrossRef] [PubMed]

16. Khorana, N.; Purohit, A.; Herrick-Davis, K.; Teitler, M.; Glennon, R.A. gamma-Carbolines: Binding at 5-HT5A serotonin receptors. Bioorg. Med. Chem. 2003, 11, 717-722. [CrossRef]

17. Liu, Y.; Song, H.; Huang, Y.; Li, J.; Zhao, S.; Song, Y.; Yang, P.; Xiao, Z.; Liu, Y.; Li, Y.; et al. Design, synthesis, and antiviral, fungicidal, and insecticidal activities of tetrahydro- $\beta$-carboline- 3 -carbohydrazide derivatives. J. Agric. Food Chem. 2014, 62, 9987-9999. [CrossRef]

18. Shen, Q.; Zhou, W.; Li, H.; Hu, L.; Mo, H. ROS involves the fungicidal actions of thymol against spores of Aspergillus flavus via the induction of nitric oxide. PLOS ONE 2016. [CrossRef]

19. Ghosh, P.; Roy, A.; Hess, D.; Ghosh, A.; Das, S. Deciphering the mode of action of a mutant Allium sativum Leaf Agglutinin (mASAL), a potent antifungal protein on Rhizoctonia solani. BMC Microbiol. 2015, 15, 1-16. [CrossRef]

20. Li, Y.; Chang, W.; Zhang, M.; Li, X.; Jiao, Y.; Lou, H. Diorcinol D exerts fungicidal action against Candida albicans through cytoplasm membrane destruction and ROS accumulation. PLoS ONE 2015. [CrossRef]

21. Childress, E.S.; Kharel, Y.; Brown, A.M.; Bevan, D.R.; Lynch, K.R.; Santos, W.L. Transforming sphingosine kinase 1 inhibitors into dual and sphingosine kinase 2 selective inhibitors: Design, synthesis, and in vivo activity. J. Med. Chem. 2017, 60, 3933-3957. [CrossRef] [PubMed]

22. Yan, X.; Liang, X.; Jin, S.; Lv, J.; Yu, C.; Qi, W.; Li, B.; Yuan, H.; Qi, S.; Shi, Y. Primary study on mode of action for macrocyclic fungicide candidates (7B3, D1) against Rhizoctonia solani Kühn. J. Agric. Food Chem. 2010, 58, 2726-2729. [CrossRef] [PubMed]

23. Zhang, J.; Zhang, Z.; Shu, B.; Cui, G.; Zhong, G. Cytotoxic and apoptotic activity of the novel harmine derivative ZC-14 in Sf9 cells. Int. J. Mol. Sci. 2018, 19, 811. [CrossRef] [PubMed]

(C) 2018 by the authors. Licensee MDPI, Basel, Switzerland. This article is an open access article distributed under the terms and conditions of the Creative Commons Attribution (CC BY) license (http://creativecommons.org/licenses/by/4.0/). 